\title{
PERCEPTION OF RISKS ASSOCIATED WITH THE DOPING USE AMONG THE COMPETITORS PRACTICING INDIVIDUAL AND GROUP SPORT DISCIPLINES Perception of risks associated with the doping
}

\author{
HELENA MROCZKOWSKA
}

\author{
Institute of Sport in Warsaw, Department of Psychology
}

\begin{abstract}
Mailing address: Helena Mroczkowska, Institute of Sport, Department of Psychology, 2/16 Trylogii Street, 01-982 Warszawa, tel.: +48 228340812 ext. 254, fax: +48 22 8350977, e-mail: psycho@insp.waw.pl
\end{abstract}

\begin{abstract}
Introduction. The aim of this study was the research among athletes whether and to what extent the sport discipline practiced (individual or team competition) influences the perception of risk associated with the use of doping in sport, and whether age and experience translates into the sports perception of the risks of doping. Material and methods. Three groups of athletes diverse was studied because of the nature of the sport task and the experience/time of practice. Individual disciplines were represented by combat sports $(n=12$, average time of practice $\sim 6$ years), group games by football players ( $n=9$, average time of practice $\sim 7$ years) and volleyball players ( $n=13$, average time of practice $\sim 14$ years .) The technique "Perception of risk of doping" was used to measure: a) the ranking of values that one can afford to lose in consequences of doping; b) the real probability of losing cherished values; c) personally acceptable level of risk associated with loss of value. Results. It was shown that young players who are members of the team are less mature and aware of the risks associated with the use of doping, not only from their older colleagues in the team, but also from their peers, competing individually. In the perception of young players there were both errors in risk assessment (distortion of losses) as well as illusions relating to the control of hazards, and unrealistic optimism about the possibility of avoiding the negative effects of doping. For mature players, the fear of losing public image has proven to be a strong deterrent against the temptation to use of illegal drugs; for young players, a relatively stronger remedy was the fear of losing the attributes of health and physical attractiveness. Conclusion. Due to the small size of the groups, these findings are suggestions that may serve as an inspiration for research on the wider population.
\end{abstract}

Key words: doping, risk, cherished values

\section{Introduction}

Regularity developed by the experimental psychology of decisions reveal in humans a general aversion to the risk of incurring losses $[1,2,3]$. The experiments arranged in the area of financial risk have shown that if we lose PLN 1 we must gain PLN 2 to compensate for the grief after the initial loss. Subjective value of the loss is twice the value assigned to the profit of the same absolute value.

Research carried out among young athletes is a part of the above observations and shows no simple relationship between knowledge of the consequences of doping and the attitude towards this phenomenon and the obvious discre- pancy between the perception of objective and personally acceptable risk $[4,5,6]$. The results suggested that a fair estimation of risks associated with the use of doping more depends on what you lose than on what can be gained, and the estimation of personally acceptable risk, given the real threat of losing valued assets, everything one can lose turns out to be equally valuable.

Psychological research (mainly laboratory) showed that the average level of risk accepted by the group is higher than the average level of risk accepted by the individual - a phenomenon is known as the risky shift. It has been confirmed in many studies and psychological experiments, including both random situations and sports performances 
that, with reasonable certainty, this pattern can be considered as also typical for the sport [7].

The aim of this study was to answer two questions. First, whether individual or team nature of the sporting task is related to the perception of the size of objectively existing and personally acceptable risk associated with doping. Second, whether the player's age and his experience/practice in sports translates into inclination to perceive the doping threats and to personal acceptance of risk associated with its use.

\section{Material and methods}

Three groups of athletes was studied: two representing the team disciplines (team of youth football players $(n=9$, average age 17.3 years and 7.2 years of training experience) and a league volleyball team $(n=13$, average age 26 years and of 13.5 years of training experience) and a group of students of the Sport Championship School practicing combat sports $(n=12$, average age 17.2 years and 5.8 years of training experience). In order to provide the subjects with a sense of security, and thus to obtain reliable data, the principle of anonymity was adopted - experimental studies have shown that the relationship between the statement and the actual behaviour is weak and explains only $10 \%$ of the variance [8].

The experimental technique of evaluation/estimation of the ability to control risk "The perception of the doping use risk" was applied $[4,8]$. The score scale allowed to see the opinions, which values selected in the pilot polls the player may lose as a consequence of the use of drugs outside of medical purposes, such as:

$>$ loss of health;

> loss of the medal, punctuated place;

$>$ loss of physical attractiveness;

$>$ loss of mental balance;

$>$ loss of financial gratification;

$>$ loss of respect of important people in the environment.
Data obtained using the Scale cover three areas:

1. Individual ranking of cherished values, specifying the size of possible losses as a result of doping - the task of the person being tested was to rank the above selected values according to the degree of difficulty - easiness to reconcile with the loss of each of them. A score of 1 to 6 points was adopted, where the higher numerical value meant that the test assigns a higher importance to the value.

2. Substantial likelihood of value loss as a result of doping - the task of the person being tested was to highlight on a percentage scale (from 0 to $100 \%$ ) the real risk of loss of each of the six values, independently of each other.

3. Subjective acceptance of the risk associated with the loss of given value resulting from the use of doping - the task of the person being tested was to identify the on a scale of 0 $100 \%$, what risk of losing any of the values the person would be willing to take and accept.

Statistical analysis of the results was conducted by $X^{2}$ function in form of $F$ function [9].

\section{Results}

Table 1 shows the estimated weight values assigned to each tested value by a particular group of subjects.

Data interpretation included two criteria of division of the test subjects: task- and age-related.

Players performing different tasks in sports of the same age (individual - team competition) showed differences in the assessment of the two values. In the perception of young representatives of combat sports, the importance of medals was significantly more valued than in the perception of young players on the team. For the latter, the loss of the medal appears to be the least important consequence of doping. The players in the youth team valued emotional balance significantly higher than participants competing individually.

Table 1. Approximate weights assigned to values that one can lose as a consequence of doping (mean \pm SD)

\begin{tabular}{|c|c|c|c|c|c|c|c|c|}
\hline $\begin{array}{l}\text { Approximate } \\
\text { values } \\
\text { of competition }\end{array}$ & Age & Experience & Health & Medals & $\begin{array}{l}\text { Physical attrac- } \\
\text { tiveness }\end{array}$ & Esteem & $\begin{array}{l}\text { Financial grati- } \\
\text { fication }\end{array}$ & $\begin{array}{l}\text { Mental } \\
\text { balance }\end{array}$ \\
\hline $\begin{array}{c}\text { Individual } \\
\mathrm{n}=12\end{array}$ & $17.1 \pm 0.5$ & $7.8 \pm 2.4$ & $4.7 \pm 1.7$ & $3.6 \pm 1.4^{*}$ & $3.4 \pm 1.7^{*}$ & $3.8 \pm 1.3$ & $2.3 \pm 1.6$ & $3.3 \pm 1.9$ \\
\hline $\begin{array}{l}\text { 1st league team } \\
n=13\end{array}$ & $26.0 \pm 2.8^{* *}$ & $13.5 \pm 3.9^{* * *}$ & $4.7 \pm 1.0$ & $3.1 \pm 1.6$ & $1.8 \pm 0.9$ & $5.1 \pm 1.3^{*}$ & $2.2 \pm 1.0$ & $4.1 \pm 1.6$ \\
\hline $\begin{array}{l}\text { Junior team } \\
\qquad n=9\end{array}$ & $17.3 \pm 0.5$ & $7.2 \pm 1.3$ & $4.4 \pm 1.9$ & $2.1 \pm 1.2$ & $2.4 \pm 1.5$ & $4.7 \pm 1.4$ & $2.6 \pm 1.1$ & $4.8 \pm 0.7^{\circ}$ \\
\hline
\end{tabular}

${ }^{*} \mathrm{p}<0.05 ;{ }^{* *} \mathrm{p}<0.001$ 
Taking into account the age criterion two groups of players were compared, homogeneous due to the team implementation of the task (football - volleyball), but diverse because of the experience in life and sports (youth team $-1^{\text {st }}$ league team). Despite differences in age and sports seniority, no substantial differences in value ranging between the two groups were observed. The three main values, although in a different configuration, focused perception of an experienced and youth teams (respect the environment, health, emotional balance.) Only the arrangement of controlled values in the structure of the pyramid indicates a flattening in the youth team - the ratio of maximum and minimum values is valued as 4.8 to 2.1 . In the $1^{\text {st }}$ league team a greater polarization of the estimated weights attributed to the values was observed - the ratio between the highest and least appreciated, is as 5.1 to 1.8 points. These data suggest that along with the experience more certainty to what is important and what is less important in life is acquired. The distributions of values in the group practicing combat sports confirms the above suggestion.

On the other hand, when comparing the young representatives of the individual disciplines with the experienced players in the team, one will see a different attitude towards the two values: the former significantly higher valued the exterior attractiveness, and for older players social recognition is more important.

The substance of controlled value as goods that may be lost in consequence of the doping also includes the temporal criterion, taking into account the time of "execution" and, therefore, feeling of loss sustained. Receiving a medal or bulleted place, loss of financial gratification and respect of the environment take place immediately after the disclosure of doping "slip". On the other hand, loss of health, emotional balance and physical attractiveness belong to the deferred consequences, which may manifest themselves at such a distant time that they are invisible or elusive immediately after the incident. The time of "execution" relates to the experience of loss of value as something more or less personal. The values of the deferred consequences belong to benefits that constitute internal integration - the personal identity. Values, which results in immediate loss are more likely to belong to external goods.

Accordingly, Table 2 shows the numerical and percentage distribution of choices assigned to the values of deferred and immediate consequences by three groups of subjects. The schedule takes into account the frequency of rating the highest and lowest ranking for each of the values, so that it more accurately describes the perception of both types of doping as a consequence of individual choice.
Table 2. Frequency of rating (\%) the highest and lowest values in accordance with ranked temporal criterion (the deferred and immediate effects)

\begin{tabular}{|c|c|c|c|c|}
\hline \multirow{2}{*}{$\begin{array}{l}\text { Rank } \\
\text { of sportsmen }\end{array}$} & \multicolumn{2}{|c|}{ Highest } & \multicolumn{2}{|c|}{ Lowest } \\
\hline & $\begin{array}{l}\text { Immediate } \\
\text { loss }\end{array}$ & $\begin{array}{l}\text { Deferred } \\
\text { loss }\end{array}$ & $\begin{array}{l}\text { Immediate } \\
\text { loss }\end{array}$ & $\begin{array}{l}\text { Deferred } \\
\text { loss }\end{array}$ \\
\hline \begin{tabular}{|l|} 
Individual \\
$n=12$
\end{tabular} & $\begin{array}{c}2 \\
16.7 \%\end{array}$ & $\begin{array}{c}10 \\
83.3 \%^{*}\end{array}$ & $\begin{array}{c}6 \\
50 \%\end{array}$ & $\begin{array}{c}6 \\
50 \%\end{array}$ \\
\hline $\begin{array}{l}1 \text { st league team } \\
n=13\end{array}$ & $\begin{array}{c}8 \\
61.5 \%\end{array}$ & $\begin{array}{c}5 \\
38.5 \%\end{array}$ & $\begin{array}{c}6 \\
46.2 \%\end{array}$ & $\begin{array}{c}7 \\
53.8 \%\end{array}$ \\
\hline $\begin{array}{l}\text { Junior team } \\
n=9\end{array}$ & $\begin{array}{c}3 \\
33.3 \%\end{array}$ & $\begin{array}{c}6 \\
66.7 \%\end{array}$ & $\begin{array}{c}6 \\
66.7 \%\end{array}$ & $\begin{array}{c}3 \\
33.3 \% \\
\end{array}$ \\
\hline
\end{tabular}

"p $<0.05$

Given the above distinction, a general pattern is noted: the attitude of the greater protection of personal goods (most of the highest ranks - about $83 \%$ ) than financial $(16.7 \%)$ show the young people representing individual sports - the differences are significant $(\mathrm{p}<0.05)$. In turn, the attitude of the weakest protection of personal property and so the of deferred effects is manifested by experienced players of the team sports (38.5\%). Detailed analysis of the highest and lowest ranks for each of the controlled values confirms earlier observations. The focus of mature players on the ad hoc and not deferred benefits results from the particular role and the importance they attach to the affiliate needs - winning or losing the respect of the environment. For young athletes, both struggling individually and collectively, health and physical attractiveness was relatively more important.

On the other hand, the analysis of the frequency of assigning the lowest ranks for both categories of goods does not reveal significant differences between groups of athletes competing as an individuals and as a team, nor between the more experienced and young players.

In the next stage it was examined whether the experience of the player and sporting nature of the task is related to the perception of real danger of losing cherished values as a consequence of a risky decision. Table 3 shows the distributions of objective probability of risk in the three test groups.

Objective sense of the risks of loss of individual assets reflects the actual knowledge of the subjects on the operation and the negative consequences of the use of illegal drugs. These data confirm the findings of previous studies that knowledge does not necessarily translate to assessment of the probability of losing cherished values. Both young and experienced players in individual and team sports are not aware of the $100 \%$ threat of losing any of the controlled values. 
Table 3. Percentage distribution of the recognition of the risks associated with the loss of cherished values (mean \pm SD)

\begin{tabular}{|l|c|c|c|c|c|c|}
\hline $\begin{array}{r}\text { Value } \\
\text { Type } \\
\text { of competition }\end{array}$ & Health & Medals & Physical attractiveness & Respect & Financial gratification & Mental balance \\
\hline $\begin{array}{l}\text { Individual } \\
\mathrm{n}=12\end{array}$ & $82.1 \pm 18.9$ & $50.8 \pm 33.6$ & $41.3 \pm 22.7$ & $50.4 \pm 22.0$ & $38.3 \pm 23.5$ & $53.1 \pm 36.8$ \\
\hline $\begin{array}{l}1 \text { st league team } \\
\mathrm{n}=13\end{array}$ & $85.4 \pm 14.1$ & $77.3 \pm 25.0$ & $65.4 \pm 28.7$ & $84.2 \pm 23.8$ & $60.0 \pm 34.2$ & $78.5 \pm 19.0$ \\
\hline $\begin{array}{l}\text { Junior team } \\
\mathrm{n}=9\end{array}$ & $87.2 \pm 14.4$ & $75.2 \pm 27.4$ & $50.6 \pm 25.5$ & $81.7 \pm 22.8^{*}$ & $61.1 \pm 28.4$ & $75.3 \pm 21.1$ \\
\hline
\end{tabular}

In each of the tested groups the highest real threat is concerned with what is valued most - the value of health and "objective" probability of its loss falls in the range from $\sim 82$ to $\sim 87 \%$. The direct external sanctions, such as loss of medal and financial gratification, which are obvious in a situation of doping "slip", are not perceived as more likely than long-time personal consequences. Experience in sport and sporting tasks have no impact on that assessment.

A general pattern was also observed: the representatives of the team games objectively assess higher the likelihood of losses than their counterparts from the individual sports - this trend applies to all assets assessed. With regard to the threat of losing the respect due to doping, these differences were significant $(\mathrm{p}<0.05)$.

In the same way the percentage of subjective risk area, that is personally acceptable probability of loss of cherished assets, was examined for each of the three groups. Table 4 presents the data in this regard.

In each of the three groups the personally acceptable, and therefore subjectively perceived level of risk associated with the consequence of doping is lower than the level considered to be an objective probability. Disagreements between the real risk perception (knowledge), and personally acceptable (decision) suggests that in thinking about doping, athletes are more daring than in the actual situation of decision-making on the use of illegal drugs.

Within the range of personally permissible risk some regularity was revealed, which supports the influence of both the experience and the kind of rivalry on the subjective sense of risk.

Players in the team, both experienced and at the threshold of maturity, accept significantly higher personal risk than the young individual players. When one compares the young players performing different sports tasks, significant differences are evident in the emotional balance. This means that the young team players are willing to personally accept a higher risk of losing mental balance than the athletes who practice individual sports $(\mathrm{p}<0.05)$.

In turn, the impact of experience on personally acceptable risk revealed in relation to the three controlled values. Older players (1 $1^{\text {st }}$ league team) accept a significantly lower health risks $(19 \%)$ and respect of the environment $(23 \%)$ than less experienced players $(48 \%, 50 \%)$ and allow a higher risk of loss of financial gratification than the youth team players (like $53 \%$ to $29 \%$ ).

Similarly, as suggested by distributions of the highest and lowest ranks accorded to each of the controlled value, for the older players a strong deterrent against the use of doping was the loss of the attributes of personal identity and social cohesion. Moreover, among the experienced players, the relationship between the value that one can lose as a consequence of doping and the level of acceptable risk of that loss was noted - health and environmental respect valued most by them are subject to the lowest conceivable risk.

Table 4. Distribution of subjectively perceived risk of doping use (mean \pm SD)

\begin{tabular}{|c|c|c|c|c|c|c|}
\hline of competition & Health & Medals & $\begin{array}{l}\text { Physical attrac- } \\
\text { tiveness }\end{array}$ & Respect & $\begin{array}{l}\text { Financial gratifi- } \\
\text { cation }\end{array}$ & Mental balance \\
\hline $\begin{array}{l}\text { Individual } \\
n=12\end{array}$ & $31.25 \pm 33.6$ & $39.58 \pm 25.5$ & $31.67 \pm 38.4$ & $29.58 \pm 17.6$ & $32.08 \pm 30.7$ & $29.58 \pm 22.4$ \\
\hline $\begin{array}{l}1^{\text {st }} \text { league team } \\
n=13\end{array}$ & $18.8 \pm 28.2^{*}$ & $59.6 \pm 35.4$ & $50.0 \pm 24.2$ & $22.7 \pm 29.6^{*}$ & $52.7 \pm 27.6^{*}$ & $32.5 \pm 30.7$ \\
\hline $\begin{array}{l}\text { Junior team } \\
n=9\end{array}$ & $48.0 \pm 37.0$ & $35.0 \pm 18.5$ & $39.44 \pm 21.6$ & $50.33 \pm 28.8$ & $28.89 \pm 16.4$ & $55.0 \pm 32.7^{*}$ \\
\hline
\end{tabular}

${ }^{*} \mathrm{p}<0.05$ 
On the other hand, in the eyes of young players the greater threat was the external threat of losing benefits acceptable level of loss of the medal and financial gratification was relatively lower than other values $(29 \%, 35 \%)$.

Among young athletes, cause-effect relationship between what they value and that they personally accept are weak or none. No relation between what is valued and how it is protected is observed particularly in the youth team. In relation to the two values most cherished by them (mental health, respect) they would take relatively the highest risk of losing them $(\sim 30 \%, 55 \%)$.

\section{Discussion}

The data obtained suggests a "big jump" in the maturation of the emotional-cognitive and social life over a decade of the young athlete's life. Logical and coherent way of thinking about doping of the experienced players - what they value most, protect most - indicate the understanding of cause-effect relationships and the skills of evaluation and managing the consequences of risky decisions. The results obtained do not give rise to the inference that with the age a greater acquiescence to the violation of the principles of sports ethics comes [10]. Fear of mature players of "losing face" and public image seems to be a potent scarecrow before the easy temptation of doping.

Similar conclusions cannot be drawn as to the young players - we have the right to think about a little conscious and mature attitude towards doping on the threshold of maturity [8, 11]. Poor understanding of doping by the young, superficial vision of its impact and dependencies and failure to see the dependence of thoughts and beliefs with action is illustrated by lack of consistency between what is valued, what one knows about the possible consequences and losses and the level of risk personally accepted. In the perception of young athletes, especially playing as a team, both the error in the assessment of risk - the distortion of losses, and error in confusion illusion of hazard control and unrealistic optimism about avoiding negative consequences can be seen.

These distortions in doping risk perception are indeed affected by the very fact of being in a social group [12, 13]. Emotional bond, and rules of intra-personal communication shaping the personal sense of security and reducing fear in the hypothetical situation of risk, rather promote reckless approach to doping than prudence. As demonstrated by the study, young player on the team is less mature and aware of the risks not only from the older teammates, but also from the peers competing individually - "maverick" in relation to any of the controlled value would not have taken such a high risk, as his coeval in the team [14].

Daring attitude of young players in the team, the lack of trans-situational compatibility between objective and personally acceptable risk and no translation of knowledge and beliefs about the effects of doping to the decision processes, point to a multidimensional and complex interaction of social groups on awareness and attitude of its member.

Due to the small size of the tested groups, the shown above observations and inferences should be treated with caution. Intentionally, the present area of study was aimed to show the meaning of such searches, and be inspiration to carry them out on a much larger group of athletes.

\section{Conclusions}

1. The knowledge of operation and consequences of doping among both young and experienced players, both playing in the team and individually, appears to be comparable. Both see in the doping use a greater objective risk to these values, which are highly valued. Real likelihood of external sanctions (loss of the medal, gratification) is not assessed as being more obvious than during the distant personal consequences (e.g. physical and mental health).

2. In the perception of the young and experienced players a real risk of loss of assets in consequence of doping is rated moderately high (about $60 \%$ to $87 \%$ ). This observation seems to be an optimistic sign of knowledge about the effects of doping and sealing of doping control [6, 15].

3. Both younger and older players in the hypothetical situation of deciding on doping use appear to be significantly less daring than their knowledge of the possible consequences of its use would indicate.

4. Along with age and the experience acquired, and thus lifetime education the desire to risk loss, especially of what is valued most, decreases, the concern for public image, sensitivity to public perception and sports image to the fans and the wider environment increases.

5. The young players are more sensitive than the older to the threat of loss of physical attractiveness, which in their perception of the world is an attribute of health and both of these values can be treated by them as the same or related goods. 


\section{Literature}

1. Gilovich, T., Griffin D. \& Kahneman D. (2002). Heuristics and biases: The psychology of intuitive judgment. New York: Cambridge University Press.

2. Kahneman, D. \& Tversky A. (2000). Values and frames. New York: Cambridge University Press.

3. Tyszka, T. (1999). Psychological Pitfalls of Evaluation and Decision Making. Gdańsk: GWP. [in Polish]

4. Mroczkowska, H. (2007). Perception of the real and subjective risk of doping. Med. Sport. 23(2), 86-90. [in Polish]

5. Mroczkowska, H. (2009). Moral attitudes in youth sport toward doping in sports. Biol. Sport 26(3), 235-243.

6. Rychta, T., Mikołajczyk M. \& Guszkowska M. (1992). Knowledge and attitudes towards pharmacological doping vs. selected personality features. Wychow. Fiz. Sport 3, 59-68. [in Polish]

7. Goszczyńska, M. (1997). Man against the Risks. Psychosocial Factors of Risk Assessment and Acceptance. Warszawa: Żak. [in Polish]

8. Mikołajczyk, M. (1991). Competition and moral level of behaviour in athletes. In J.R. Nitsch \& R. Seiler (Eds.), Motivation, emotion, stress (Proceeding of VIII European
Congress of Sport Psychology; 1, 81-85). Köln: Academia Verlag \& Sant Augustin.

9. Sokal, R.R. \& Rohlf F.J. (1998). Biometry (3 ${ }^{\text {rd }}$ edition). USA, San Francisco: W.H. Freeman \& Co.

10. Cruz, J., Boixados M., Valiente L. \& Villamorin F. (2001). Values, socio-moral attitude and achievement goals among youth team sports participation in Spain $(2,195-$ 197). In $10^{\text {th }}$ World Congress of Sport Psychology.

11. Weinstein, N.H. (1998). Taking Care: Understanding and Encouraging Self-protective Behaviour. Cambridge: CUP.

12. Clark, R.D. (1971). Group-Induced shift toward risk: a critical appraisal. Psychological Bulletin 4, 68-76.

13. Mroczkowska, H. (2002). Individual and group capacities of sport team. Biol. Sport 1(19), 91-100.

14. Mroczkowska, H. (2008). Influence of social group on perception of risky decision of doping use in sport. Sport Wyczyn. (in print). [in Polish]

15. Rychta, T., Mikołajczyk M. \& Guszkowska M. (1993). Opinions and attitudes of sports championship school students against athletic doping. Sport Wyczyn. 5-6, 7787. [in Polish]

Submitted: July 30, 2010

Accepted: October 27, 2010 